\title{
Giant Hyalinizing Trabecular Carcinoma of the Thyroid Gland in a 20-Years Old Male Patient
}

\author{
Michael S Papageorgiou \\ Department of Endocrine Surgeon, American Medical Center, Cyprus
}

Submission: November 8, 2018; Published: November 21, 2018

*Corresponding author: Michael S Papageorgiou, Department of Endocrine Surgeon, American Medical Center, Nicosia, Cyprus

Abstract

Hyalinizing trabecular tumors (HTT) are a rare and relatively young entity in thyroid pathology. They are tumors that are frequently mistaken for papillary or medullary carcinomas and they are characterized by the trabecular growth pattern and hyalinizing stroma. Most of them are benign, but there are few reports of malignant behavior (capsular invasion, metastases etc.) We report a case of a 20 -years-old male with a 6,5cm left lobe thyroid nodule, who was treated with total thyroidectomy and level VI lymph nodes dissection. The final pathology diagnosed the tumor as a Hyalinizing trabecular carcinoma (HTC).

Keywords: Hyalinizing trabecular carcinoma; Hyalinizing trabecular tumor; thyroid

\section{Introduction}

Hyalinizing trabecular tumors were first described in 1987 by Carney et al. [1] who reported a series of 11 cases that they were categorized as HTTs, while the distinctive features of these tumors were the trabecular cell growth pattern and the hyalinizing stroma [1]. Ever since, it was believed that these tumors were completely benign, with only a handful of exceptions. To add in the controversy, in everyday practice, these tumors were often misdiagnosed as papillary carcinomas or medullary carcinomas. To answer this controversy, World Health Organization (WHO) classified these tumors as Hyalinizing trabecular tumors (HTTs), thus including adenomas and carcinomas in a mixed category [2]. HTTs affect mainly the female population (male to female ratio 1:6) [2,3]. Although cases were reported between 20 and 80 years old, the mean age of diagnosis is 50,5 years-old. We report a rare case of a 20 -years-old male with a gigantic $(6,5 \mathrm{~cm})$ Hyalinizing trabecular carcinoma (HTC). Diagnosis and treatment are presented, and some key points of the literature are discussed.

\section{Case Report}

A 20-years-old male patient presented to the Outpatient Department with a large cervical mass, extending predominantly to the left side. Family members stated that he had the mass for many years (at least 4 years), although not as big as it was at present. The patient had no previous medical conditions and there was not any family history of thyroid diseases. An ultrasound and a CT scan demonstrated a large nodule of the left thyroid lobe, measuring $9 \times 6,5 \times 5 \mathrm{~cm}$ and two smaller cystic nodules in the right lobe. Lymph nodes ultrasonic investigation demonstrated mildly enlarged level VI nodes, with no evidence of infiltration, while an FNA of the large mass showed a Thy-4 neoplasm, suspicious for papillary carcinoma. Considering the size of the tumor and the evidence of lymph nodes participation, a total thyroidectomy with level VI lymph nodes dissection was proposed and finally performed. In surgery, a neuromonitoring device was used and both recurrent laryngeal nerves and 4 parathyroid glands were identified and saved. The postoperative course was uneventful, and the patient was discharged on the first postoperative day, with calcium supplements and thyroxin tablets. Final pathology stated that the large mass was a Hyalinizing trabecular carcinoma. Detailed description stated that the tumor cells were arranged in elongated trabeculae and in one point the tumor extended through the adjacent capsule in an invasive growth pattern. Immunotoxins showed positivity for PAX8 and TTF-1, while chromogranin and calcitonin were negative. Ten (10) lymph nodes that were removed, proved to be negative for malignancy. Patient was referred for RAI treatment and it was performed with any indications of persistent or recurrent disease $(\mathrm{Tg}<0,1 \mathrm{ng} / \mathrm{ml}$ with TSH 78,3 $\mu \mathrm{IU} / \mathrm{ml})$. Afterwards, the patient was under close follow-up, and 2 years since, he is free of any indications of recurrence.

\section{Discussion}

Hyalinizing trabecular tumors (HTT) are a new entity in thyroid pathology. The tumors show some mutual characteristics with papillary carcinomas (RET/PTC rearrangements) thus leading some experts believe that they are merely a subtype of papillary carcinomas instead of a distinct category [4]. Other cases are mistaken as medullary carcinomas, non-invasive follicular thyroid neoplasm with papillary-like nuclear features (NIFTP) or even as paragangliomas [5]. Diagnosis is made as in every other thyroid nodule. Ultrasonography features are general and usual- 
ly include hypo echogenicity or marked hypo echogenicity in the absence of other suspicious features (calcifications etc.) FNA results are often misleading as well. A previous study showed that only $8 \%$ of HTTs were diagnosed preoperatively with FNA and an additional 6\% was only suspected. Most of the times FNA reports indicate a possibility or even a certainty for papillary carcinoma (55\%-60\%) [5,6]. In our case, the FNA report was highly suspicious for papillary carcinoma, with a possibility of $60 \%-75 \%$. To add up to the controversy, most authors considered HTTs to be always benign. In the following years though, cases were reported with malignant behavior, such as lymph nodes and pulmonary metastases, or detection of BRAF mutations [7-9]. Unfortunately, these few cases cannot be surely distinguished by FNA, core biopsy, or even frozen section during surgery (only 53\% could be diagnosed correctly) [10]. In our patient, we performed a total thyroidectomy with central compartment lymph nodes dissection, based on the high suspicious for PTC and the possible lymph nodes participation. Treatment is also an issue for debate. Since the majority of HTTs are benign, a lobectomy is the treatment of choice for these lesions. But taking in concern that even a few cases have a malignant potential and can lead to metastatic disease, a completion thyroidectomy and RAI treatment must be performed in these patients $[2,10,11]$. Our case presented in this report, is a very rare case of an HTC. The patient was male, in a young age, with a very large tumor. Malignancy was established by a microscopic invasion of the capsule by the tumor cells. Although the size of the tumor was large, lymph nodes removed were negative for infiltration and the postoperative course indicates a relatively low malignant potential.

\section{Conclusions}

In conclusion, Hyalinizing trabecular tumors represent a relatively new, rare and understudied part of thyroid pathology. Most of the knowledge acquired is by case reports or a few small case series in the literature. In our opinion, large multicentral studies should be designed, in order to address these following significant questions.

- What is the true malignant potential of these tumors?

- How can we increase our chances for a correct preoper-

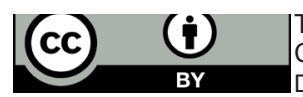

This work is licensed under Creative Commons Attribution 4.0 Licens DOI: 10.19080/JETR.2018.04.555626 ative diagnosis, in order to avoid unnecessary total thyroidectomies and identify only the malignant ones?

- Is a lobectomy the preferred treatment in these tumors from start? What should be our surgical strategy for these patients? Is there a need for prophylactic lymph nodes dissection if there is a possibility or certainty for malignancy?

- Is RAI treatment needed in these patients? And if yes, what is the survival rate in malignant cases?

\section{References}

1. Carney JA, Ryan J, Goellner JR (1987) Hyalinizing trabecular adenoma of the thyroid gland. Am J Surg Pathol 11: 583-591.

2. Li J, Yang GZ, Gao LX, Yan WX, Jin H, et al. (2012) Hyalinizing trabecular tumor of the thyroid: Case report and review of the literature. Exp Ther Medm 3(6):1015-1017.

3. Dustin J Jones, Christopher R Kieliszak, Sanjay S Patel, Christopher R Selinsky (2017) Hyalinizing trabecular tumor of the thyroid gland and its significant diagnostic issue. Thyroid Research 10: 7

4. Román-González A, Simán-Duque C, Camilo-Pérez J, Vélez-Hoyo A (2016) Trabecular hyalinizing adenoma of the thyroid (HAT): A report of two cases. Gac Med Mex 152(1): 111-115.

5. Saglietti C, Piana S, La Rosa S, Bongiovanni M (2017) Hyalinizing trabecular tumour of the thyroid: fine-needle aspiration cytological diagnosis and correlation with histology. J Clin Pathol 70(8): 641-647.

6. Jang H, Park CK, Son EJ, Kim EK, Kwak JY, et al. (2016) Hyalinizing trabecular tumor of the thyroid: diagnosis of a rare tumor using ultrasonography, cytology, and intraoperative frozen sections. Ultrasonography 35(2):131-139.

7. Gowri shankar S, Pai SA, Carney JA (2008) Hyalinizing trabecular carcinoma of the thyroid gland. Histopathology 52(4): 529-531.

8. Li X, Fu Y, Li B (2014) Hyalinizing trabecular carcinoma of thyroid: report of a case. 43(2): 130-131.

9. Kondo T, Nakazawa T, Terada N, Nakazawa K, Kawasaki T, et al. (2012) Unusual thyroid carcinoma with excessive extracellular hyaline globules: a case of hyalinizing papillary carcinoma. Hum Pathol 43(6): 932-938.

10. Sung SY, Shen HY, Hsieh CB, Duh QY, Su TF, et al. (2014) Hyalinizing trabecular tumor of thyroid: does frozen section prevent unnecessarily aggressive operation? Six new cases and a literature review. J Chin Med Assoc 77(11): 573-577.

11. Riaz S, Bashir H, Jahangir S, Nawaz MK (2014) Hyalinizing trabecular neoplasm of thyroid. J Ayub Med Coll Abbottabad 26(3): 410-412.

\begin{tabular}{l} 
Your next submission with Juniper Publishers \\
will reach you the below assets \\
- Quality Editorial service \\
- Swift Peer Review \\
- Reprints availability \\
- E-prints Service \\
- Manuscript Podcast for convenient understanding \\
- Global attainment for your research \\
- Manuscript accessibility in different formats \\
( Pdf, E-pub, Full Text, Audio) \\
- Unceasing customer service \\
Track the below URL for one-step submission \\
https://juniperpublishers.com/online-submission.php \\
\hline
\end{tabular}

